\title{
Molds of Clinical Importance
}

\author{
Class Zygomycetes \\ Mucor \\ Rhizopus \\ Class Ascomycetes \\ Chaetomium \\ Fungi Imperfecti \\ Order Moniliales \\ Family Moniliaceae \\ Aspergillus \\ Botrytis \\ Monilia \\ Mycogone \\ Paecilomyces \\ Penicillium \\ Family Dematiaceae \\ Alternaria \\ Cladosporium \\ Helminthosporium \\ Pullularia (Aureobasidium) \\ Stemphylium \\ Family Tuberculariaceae \\ Epicoccum \\ Fusarium \\ Order Sphaeropsidales \\ Phoma \\ Class Basidiomycetes \\ Subclass Heterobasidiomycetes \\ Rusts \\ Smuts
}


